\title{
STUDY OF USE OF CAD AND CAE IN TISSUE SCAFFOLD DESIGN OPTIMIZATION AND ANALYSIS.
}

\author{
Suhas Chandrapatle \\ Department of Mechanical engineering \\ Sinhgad College of engineering, Pune, Maharashtra, India
}

\begin{abstract}
Computer-aided method traditionally use only for design and analysis of machines and its components. Because of recent development in the field of Information Technology, Mechanical engineering and Bio-medicine it is now possible to use the computer-aided technique in design, modeling and optimization of the tissue scaffold. Scaffolds plays very important role in the field of Tissue Engineering. Scaffold mainly use to provide the structural support and provide suitable micro environment for proliferation of cell for tissue regeneration phenomenon. The design and modeling of a scaffold is very tedious task because of its complicated architecture, therefore Computer-aided design (CAD) and analysis method is use for design and analysis of tissue scaffolds. This review paper describe the Computer based scaffold's 3D CAD model generation technique using reverse engineering approach, Finite element analysis method of the scaffold for design optimization and simulation of scaffold 3D model and need of computational engineering in scaffold modeling and simulations.
\end{abstract}

Keywords - CAD, CAE, Tissue engineering, Tissue scaffold, FEA, Bio-CAE

\section{INTRODUCTION}

Organ and tissue transplantation was the only solution for organ failure and tissue damaged. Although such medical therapies has some merits but shortage of organ and tissue donor increased the waiting list of patients every year. To address this organ failure crisis the new field of engineering arises, called as tissue engineering. Which is define as, application of chemical, biological and engineering towards repair, regeneration and restoration of damaged tissue using biomaterial, scaffolds and cells. Scaffolds plays important role in the tissue regeneration and new tissue formation from stem cell both in vivo as well as in vitro processes. Scaffold gives mechanical support for load bearing tissue such as bone and also porous nature of scaffold provide fluid flow through scaffold and creates suitable micro environment for proliferation of tissue for tissue regeneration. The main function of tissue scaffold is to withstand the stress, load acting on it and simultaneously provide require fluid flow through scaffold. So design such a scaffold is a difficult task because it requires to maintain strength and fluid flow simultaneously. Because of this heterogeneous and complex architecture of tissue scaffold we cannot use conventional method to design and fabrication of tissue scaffold. So now a day's computer-aided design and analysis method to tissue scaffold modeling is use. The use of computational approach in the scaffold design is possible because recent development in the field of information technology, mechanical engineering and bio-medicine created new use of computational engineering in the application biomedical and tissue scaffolds design and fabrication. Which give rise to the new field of engineering computer-aided tissue engineering (CATE). The 3D volumetric representation of tissue scaffold in computational softwares is generated using feature primitive approach and image acquisition methods. In image acquisition method the CT/MRI images of tissue is taken into MIMICS software to generate volumetric representation and then by using reverse engineering approach the CAD model is generated. And to obtain proper Hierarchical scaffold design the mathematical unit cells are selected using FEA technique and those are assembled in such way that they form scaffold architecture by using Boolean operation. Finite element analysis method is also use for simulation of tissue scaffold for scaffold design optimization. Compared with conventional method the computational method for design and fabrication of tissue scaffold is more efficient, precise and computational method also required less time and cost.

\section{LITERATURE SURVEY}

[1] W. Sun et.al (2005) Bio-CAD modeling and its applications in computer-aided tissue engineering

Presented the over view of computer-aided tissue engineering (CATE) and describes various applications of Bio-CAD modeling CATE in biomimetic and no-biomimetic tissue scaffolds modeling. Also explain the non-invasive image acquisition and reverse engineering approach for tissue scaffold's 3D CAD model generation. And Solid free form fabrication techniques for fabrication of scaffold from its $C A D$ model is also explains

[2] Hollister S. (2005) Porous scaffold design for tissue engineering

In this research paper literature explains how computer aided topology and solid free form fabrication techniques integrate for design and fabrication of tissue scaffolds. Also explains how mechanical properties and tissue regeneration is achieve 


\section{International Journal of Engineering Applied Sciences and Technology, 2020 \\ Vol. 5, Issue 3, ISSN No. 2455-2143, Pages 603-606 \\ Published Online July 2020 in IJEAST (http://www.ijeast.com)}

by design porous tissue scaffold and how important is unit cells libraries to achieve scaffold's complex architectural design is defined.

[3] Egan PF et.al (2017) computationally designed lattices with tuned properties for tissue engineering using 3D printing Developed the computational approach for modeling and design of scaffold lattice structure having eight different topologies. Where author generated lattice topology with beam based structure and for each different topology the finite elemental analysis method use for simulation and analysis of elasticity, shear stress for which they perform Beam analysis for calculation of shear and elastic modulus.

[4] Nam J. et.al (2005) Computer Aided Tissue Engineering for Modeling and Design of Novel Tissue Scaffolds

Developed the feature primitive based Reasoning Boolean Operation (RBO) for modeling of complex and heterogeneous tissue scaffolds CAD model. Where author specifically discuss the merging and extracting operations. And feature primitive based computer aided tissue engineering's various applications are explains

[5] Dernowsek JA et.al (2017) BioCAE: A New Strategy of Complex Biological Systems for Biofabrication of Tissues and Organs

In this paper author review the trends and recent studies in use of finite elemental analysis for cartilage tissue engineering and scaffold design. They also represent the application of F.E.A. in cellular activity, cell differentiation and scaffold structural optimization

\section{METHODOLOGY FOR TISSUE SCAFFOLD DESIGN}

1. Primary functions of scaffolds:-

1) Scaffold must act as an extracellular matrix (E.C.M.).

2) Scaffold provides mechanical support at a site of tissue regeneration.

3) Scaffold must provide appropriate porosity for mass and fluid transfer.

4) Scaffold create suitable micro environment for tissue growth and tissue proliferation.

\section{Need of Computational engineering in Scaffold design and simulation}

Because of complex architecture of scaffold the design and fabrication of scaffold with conventional method is tedious task it also require lots of efforts and high cost. Therefore computational approach is use. With computational method the anatomical representation of scaffold is possible using CAD and MIMICS softwares. And with the help of computational finite elemental analysis software under specified loading and boundary conditions the load acting, mechanical stress acting and fluid flow properties such as flow pressure and flow velocity can be analyzed.

\section{Scaffold design consideration:-}

1) Mechanical requirements - The properties such as porosity, stiffness, strength of a designed scaffold and tissue with which scaffold is replacing is must be similar.

2) Anatomical requirements - Shape and size of the scaffold is must be accurate such that it will correctly fit the site of replacement.

3) Biological requirements - The material use for scaffold and shape of scaffold must facilitate the attachment and dissemination of cell for new tissue growth. Scaffold must develop the suitable environment for cell growth and proliferation.

\section{Method for computer based 3D CAD model generation of heterogeneous scaffold:-}

To know the actual structure, shape and size of a site where tissue scaffold will use CT/microCT/MRI scan images of site at different height and orientation is taken which will also give the anatomical representation. Further this noninvasive image data is use for 2D segmentation. 2D segmentation is nothing but extraction of geometry of CT scan data set. The next step is $3 \mathrm{D}$ voxel based volumetric model generation. To generate 3D model specified number of image slices having specific thickness are loaded in to MIMICS software. In MIMICS this images are aligned at proper height and orientation and then Region of Interest (ROI) is defined. Region growing technique is applied for 3D model generation.

This generated 3D model cannot directly use for bio-mechanical studies. This model is capable for anatomical morphology which further use for rapid prototyping by converting into STL format. This 3D volumetric model is not capable for structural design purpose and for bio-mechanical analysis. Therefore this model has to convert into CAD model for which reverse engineering approach is use which is efficient and can be use for the complex structure also. In this method 3D voxel model is first converted into point data form by using reverse engineering software. And to form faceted model triangulation of this points are done further the refinement of model is done. And then free form surfaces of Non-uniform rational B-spline (NURBS) are use to fit across outer shape of model. 


\section{International Journal of Engineering Applied Sciences and Technology, 2020 Vol. 5, Issue 3, ISSN No. 2455-2143, Pages 603-606 \\ Published Online July 2020 in IJEAST (http://www.ijeast.com)}

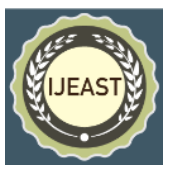

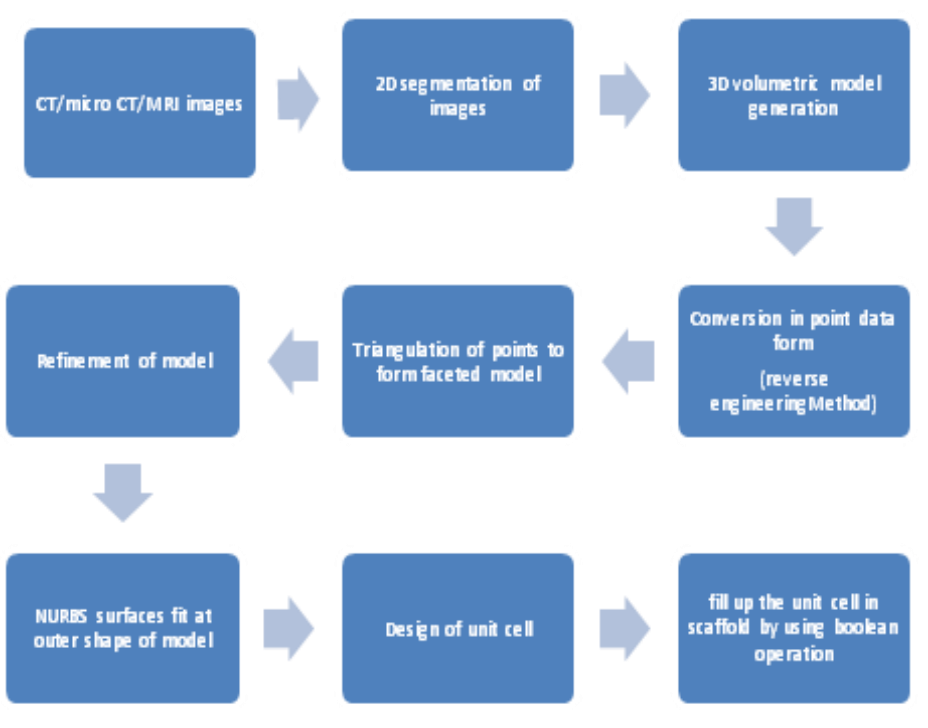

Fig 1.Road map for 3D CAD model generation of heterogeneous tissue scaffold

After design of the cad model of scaffold the next step is to design unit cell to characterize the tissue's heterogeneity. The libraries of unit cells are designed using CAD software at different scales. Finite element analysis method is use for selection of unit cells. For selection tetrahedral mesh is use for analysis. Reaction force $\left(R_{x}\right)$ is calculated and from that reaction force effective elasticity modulus $\left(\mathrm{E}_{\mathrm{xx}}\right)$ is calculated.

Formula use is,

$$
\mathrm{E}_{\mathrm{xx}}=\mathrm{R}_{\mathrm{x}} / 0.001 * \mathrm{~A} \text {. }
$$

And unit cells having mechanical properties similar to tissue characteristics are selected then they use to fill up the scaffold structure by using the Boolean operations final CAD model is generated.

\section{FINITE ELEMENT ANALYSIS OF CAD MODEL OF TISSUE SCAFFOLD}

The designed 3D CAD model of tissue scaffold cannot directly use for further processes. There might be possibility that scaffold design will fail. so for design optimization of scaffold and simulation of scaffold under specified loading and boundary condition the use of finite element analysis (F.E.A.) is necessary. This FEA analysis of CAD model of scaffold is done by computer-aided engineering software such as ANSYS.

The FEA analysis of tissue scaffold starts with meshing. The four node tetrahedral, eight and twenty nodes hexahedral are commonly use mesh for tissue scaffold. The boundary and loading conditions are applied on tissue scaffold to mimic the actual physiological environment of tissue. Static loading conditions are use for analysis of scaffold which is also most commonly use loading conditions to compute the stress distribution in tissue scaffold, yield strength and permeability. Sometimes tissue scaffold also required dynamic loading because the stress profile obtained from the static loading is not sufficient. Lower frequency dynamic loading conditions are used.

For macroscopic stiffness calculation.

$\mathrm{C}_{\text {macro }}=1 / \mathrm{V}_{\text {unit cell }} \quad$ micro $* \mathrm{M} \mathrm{dv}$ unit cell

Where, $\mathrm{M}$ is strain localization tensor.

The permeability at macroscopic level to measure the mass transfer through scaffold is calculated by formula.

$\mathrm{K}_{\text {macro }}=1 / \mathrm{V}_{\text {unit cell }} \quad \mathrm{dv}_{\text {unit cell }}$

\section{CURRENT DRAWBACKS}

(1) Because of complex architecture of scaffold it required lots of computational work for modeling and simulation of tissue scaffold and it is also a tedious task.

(2) To understand microscopic mechanical behavior of tissue scaffold with help of current software is difficult.

(3) It is unable to analyze the tissue and scaffold interaction.

(4) The presence of hidden diseases in tissue which will be replaced by scaffold may lead to failure of tissue scaffold and it is difficult to determine and control such diseases.

\section{CONCLUSION}

This paper reviews the recent computational methods for design, modeling and simulation of tissue scaffold. And explained how image based processing, feature primitive approach and reverse engineering method is use for 3D CAD model generation to get better anatomy and structural representation of tissue scaffold. The finite element analysis method for simulation and analysis of tissue scaffold is also described.

\section{REFERENCES}

[1] Sun W., Starly B., Nam J., Darling A. (2005) Bio-CAD modeling and its applications in computer-aided tissue engineering. Computer-Aided Design 37 1097-1114.

[2] Hollister S. (2005) Porous scaffold design for tissue engineering. Nature materials 518-524.

[3] Egan P., Gonella V., Engensperger M. , Ferguson S., Shea K (2017) computationally designed lattices with tuned properties for tissue engineering using 3D printing. PLOS ONE 12(8): e0182902.

[4] Nam J., Starly B., Sun W. (2005) Computer Aided Tissue Engineering for Modeling and Design of Novel Tissue Scaffolds. Drexel University 633-639. 
[5] Dernowsek J., Rezende R., da Silva JVL (2017) BioCAE: A New Strategy of Complex Biological Systems for Biofabrication of Tissues and Organs. J Tissue Sci Eng 8: 200. doi: 10.4172/2157-7552.1000200.

[6] Chaudhry H., Qin Y., Komatsu D., Sardar U.(2019) Utilization of Finite Element Analysis for Articular Cartilage Tissue Engineering. doi:10.3390/ma12203331

[7] Hoque M., Lum Weng L., Chaun Y., Ansari M (2014). computational characterization of porous and mechanical properties of 3D scaffold for potential tissue engineering application. ISSN: 2348-4098 VOLUME 02.

[8] Eltom A., Zhong G., Muhammad A. (2019) Scaffold Techniques and Designs in Tissue Engineering Functions and Purposes: A Review. Hindawi Advances in Materials Science and Engineering, Article ID 3429527, 13 pages doi $10.1155 / 2019 / 3429527$

[9] Jekhmane S., Prachar M., Pugliese R. , Fontana F., Silva M., Gelain F., Weingarth M. (2019) Design Parameters of Tissue-Engineering Scaffolds at the Atomic Scale. Angew. Chem. Int.58, 16943 - 16951

[10] Lantada A. D., Morgado P.L.,Otero J.E., Tanarro E.C., de la Guerra Ochoa E., Munoz-Guijosa J., Muñoz Sanz J.(2012) BIOMIMETIC COMPUTER-AIDED DESIGN AND MANUFACTURE OF COMPLEX BIOLOGICAL SURFACES. DOI: 10.5220/0003889002860290 In Proceedings of the International Conference on Biomedical Electronics and Devices (BIODEVICES-2012), pages 286290 ISBN: 978-989-8425-91-1.

[11] Jung JinWoo, Lee Jung-Seob, Dong-WooCho (2016) Computer-aided multiple-head 3D printing system for printing of heterogeneous organ/tissue constructs. nature Scientific Reports 6:21685 DOI: 10.1038/srep21685.

[12] Hutmacher H. W. , Sittinger Michael, Risbud Makarand (2004) Scaffold-based tissue engineering: rationale for computer-aided design and solid free-form fabrication systems. doi:10.1016/j.tibtech.2004.05.005.

[13] Gu Bon Kang, Choi Dong Jin, Park Sang Jun, Kim Min Sup, Kang C., Chun-Ho Kim(2016) 3-dimensional bioprinting for tissue engineering applications. $\mathrm{Gu}$ et al. Biomaterials Research (2016) 20:12 DOI 10.1186/s40824-016-0058-2. 